\title{
BMJ Open Efficacy of prothrombin complex concentrate (PCC) versus fresh frozen plasma (FFP) in reducing perioperative blood loss in cardiac surgery: study protocol for a non-inferiority, randomised controlled trial
}

Lijian Pei, ${ }^{1,2}$ Chen Sun (D) , ${ }^{1}$ Hong Lv, ${ }^{3}$ Yuelun Zhang (D) , ${ }^{4} \mathrm{Jia} \mathrm{Shi}^{3}$

To cite: Pei L, Sun C, Lv H, et al. Efficacy of prothrombin complex concentrate (PCC) versus fresh frozen plasma (FFP) in reducing perioperative blood loss in cardiac surgery: study protocol for a non-inferiority, randomised controlled trial. BMJ Open 2022;12:e051072. doi:10.1136/ bmjopen-2021-051072

- Prepublication history for this paper is available online. To view these files, please visit the journal online (http://dx.doi. org/10.1136/bmjopen-2021051072).

LP and CS contributed equally.

Received 10 March 2021 Accepted 13 January 2022

D) Check for updates

(C) Author(s) (or their employer(s)) 2022. Re-use permitted under CC BY-NC. No commercial re-use. See rights and permissions. Published by BMJ.

For numbered affiliations see end of article.

Correspondence to

Dr Jia Shi; shijia@fuwai.com

\section{ABSTRACT}

Objective To explore whether prothrombin complex concentrate (PCC) is not inferior to fresh frozen plasma (FFP) with regard to reducing perioperative blood loss in patients undergoing cardiac surgery under cardiopulmonary bypass (CPB).

Setting Fu Wai Hospital, and Peking Union Medical College Hospital in China.

Participants Patients undergoing elective coronary artery bypass grafting, valve replacement or valvuloplasty under CPB, between 18 and 80 years old, will be included.

Design This study is a non-inferiority, randomised controlled clinical trial. A total of 594 subjects will be randomly assigned to two groups (group PCC and group FFP) and given corresponding interventions when at least one of the following criteria is met: (1) international normalised ratio $>1.7$ measured 20 min after CPB, (2) prolonged prothrombin time or activated partial thromboplastin time ( $>1.5$ times baseline) measured 20 min after CPB and (3) excessive bleeding observed. 4-factor PCC (15IU/kg) and FFP $(10 \mathrm{~mL} / \mathrm{kg})$ will be given to group PCC and group FFP, respectively. Preoperative management, anaesthetic and surgical techniques will be standardised for both groups.

Primary and secondary outcome measures The primary outcome is the volume of blood loss during and within 24 hours after surgery. The secondary outcomes include (1) the total units of allogeneic red blood cells transfused during and within 7 days after surgery, (2) reexploration due to postoperative bleeding within 7 days after surgery, (3) adverse events and serious adverse events within 30 days after surgery and (4) length of intensive care unit stay and hospital stay.

Trial registration number Registered under NCT04244981 at ClinicalTrials.gov on 28 January 2020, https://clinicaltrials.gov/ct2/show/NCT04244981?cond= NCT04244981\&draw=2\&rank=1.

Ethics and dissemination This study has been approved by the Institutional Review Board of Peking Union Medical College Hospital (ZS-2242).
Strengths and limitations of this study

- This study focuses on the efficacy of prothrombin complex concentrate, compared with fresh frozen plasma (FFP), in reducing perioperative blood loss under cardiopulmonary bypass in cardiac surgery.

- Considering the insufficiency and disadvantages of FFP, the study may provide an alternative strategy for the treatment of major blood loss in cardiac surgery.

- The limitation in this study is that the doses and time of intervention are based on guidelines and clinical practice, not having previous evidence in our own research team to provide stronger support.

\section{INTRODUCTION}

Major bleeding and allogeneic blood transfusion are major complications of cardiac surgery ${ }^{12}$ with increased risk of serious postoperative morbidities including infections, atrial fibrillation, respiratory complications, acute kidney injury, short-term and long-term mortality and increased medical costs. ${ }^{3-5}$ Compared with all other surgeries, cardiac surgery is among the highest overall rate of red blood cell (RBC) transfusion, accounting for $10 \%-15 \%$ of all RBC transfusions in the USA and the UK. ${ }^{6}{ }^{7}$ Approximately $10 \%$ of all patients who underwent cardiac surgery suffer from severe or massive blood loss, and up to $5 \%$ require emergent re-exploration in an attempt to correct ongoing bleeding and establish adequate haemostasis. ${ }^{89}$

Coagulopathy is one of the main reasons for massive perioperative bleeding and allogeneic blood transfusion in cardiac surgery and cardiopulmonary bypass (CPB). ${ }^{10}$ In addition to decreasing platelet and fibrinogen levels, coagulation factor deficiency also 
plays an important role in post-CPB coagulopathy. ${ }^{11}$ Fresh frozen plasma (FFP) and prothrombin complex concentrate (PCC) are currently used primarily to treat perioperative coagulopathy in cardiac surgery ${ }^{12}$ and suitable for increasing the concentration of vitamin K-dependent coagulation factors. FFP has been widely used to acutely treat coagulopathy in the past decades, which contains all of the necessary clotting factors and also fibrinogen. ${ }^{13}$ Compared with FFP, PCC offers several advantages in the management of cardiac surgery coagulopathy, such as faster infusion rates, lower volume overload, shorter preparation time, no blood-type matching needed and lower rate of transfusion reaction. ${ }^{14}$ In addition, in many hospitals in our country, FFP that blood banks could provide in time is always insufficient in clinical practice and often cannot meet the treatment demands of perioperative bleeding and coagulation dysfunction. Therefore, we hope to gradually reduce the use of FFP and switch to use PCC to treat perioperative coagulopathy in cardiac surgery.

A body of evidence have suggested that PCCs can provide more rapid and effective treatment for warfarin and vitamin $\mathrm{K}$ antagonists (VKA) reversal compared with FFP, with rapid international normalised ratio (INR) correction and greater increase in clotting factors. ${ }^{15-17}$ However, there are only a few studies, mostly retrospective studies, concentrating on PCC for the treatment of post-CPB bleeding, which indicate that the use of PCC is associated with less chest tube output and RBC transfusion versus FFP. ${ }^{18-21}$ Properly designed randomised controlled clinical trials (RCT) should be done to evaluate the efficacy and safety of PCC compared with FFP.

Considering the gap, we want to design an RCT to identify the efficacy of PCC compared with FFP in the treatment for coagulopathy in cardiac surgery, exploring whether PCC is not inferior to FFP in reducing perioperative blood loss in patients undergoing cardiac surgery under CPB.

\section{METHODS \\ Study design}

This is a non-inferiority RCT. The trial will be conducted at Fu Wai Hospital and Peking Union Medical College Hospital, China. A total of 594 participants will be randomised. The trial schema is shown in figure 1 , and the study period is shown in figure 2. The study will be monitored by an independent Trial Steering Committee and Data Safety Monitoring Committee.

\section{Study population}

Inclusion criteria

Eligible patients must meet all of the following criteria:

1. Age between 18 and 80 years.

2. Undergoing elective coronary artery bypass grafting $(\mathrm{CABG})$ or valve replacement or valvuloplasty through CPB.

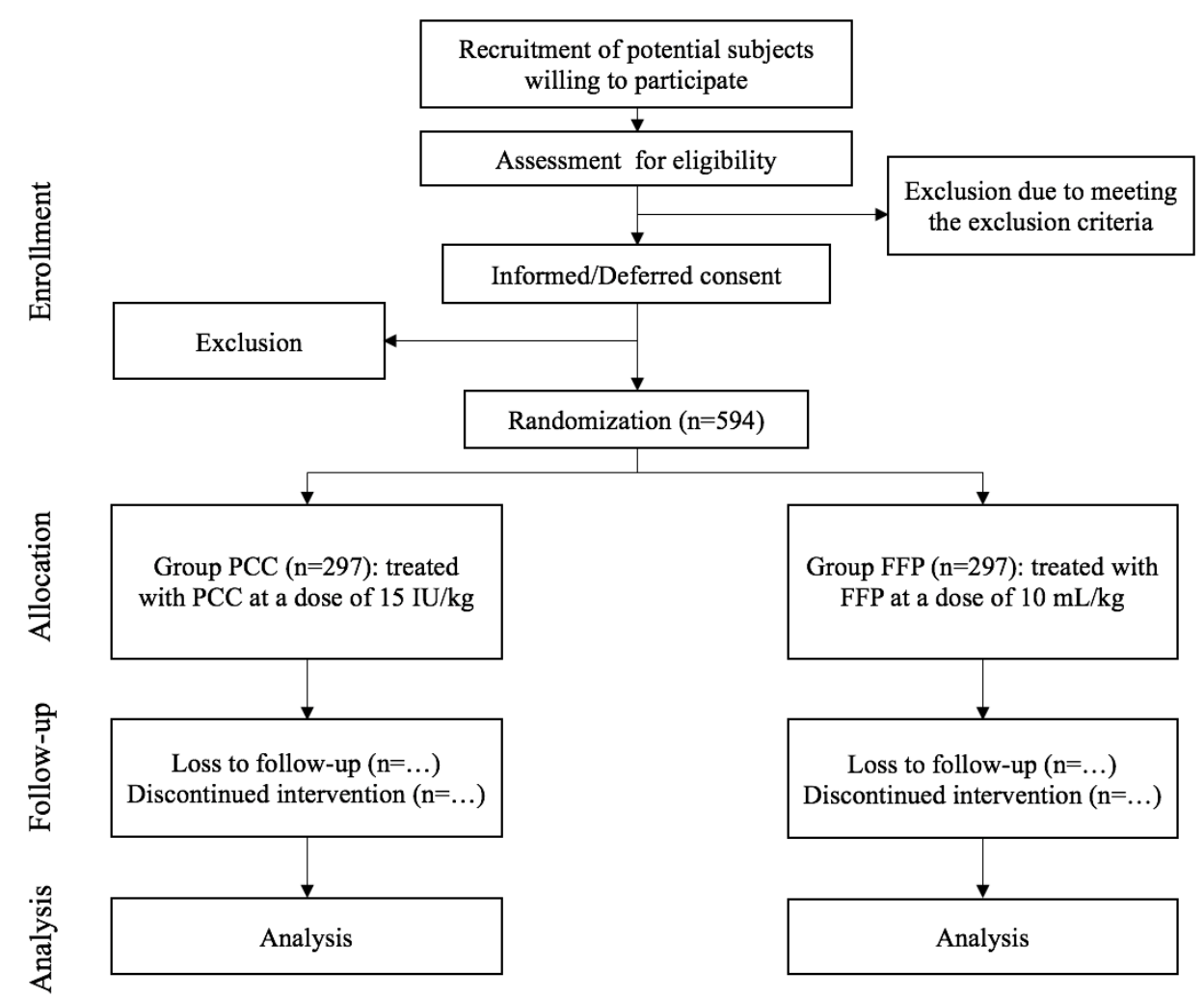

Figure 1 Study design and participant flow chart. FFP, fresh frozen plasma; PCC, prothrombin complex concentrate. 


\begin{tabular}{|c|c|c|c|c|c|c|c|c|}
\hline \multirow[b]{3}{*}{ TIMEPOINT } & \multicolumn{8}{|c|}{ STUDY PERIOD } \\
\hline & \multicolumn{2}{|c|}{ Enrolment } & \multirow{2}{*}{$\begin{array}{c}\text { Allocation } \\
\begin{array}{c}\text { 1h before } \\
\text { surgery }\end{array}\end{array}$} & \multicolumn{4}{|c|}{ Post-allocation } & \multirow{2}{*}{$\begin{array}{r}\text { Close-out } \\
\begin{array}{l}7 d \text { after } \\
\text { surgery }\end{array}\end{array}$} \\
\hline & $\begin{array}{c}\text { Within 7d } \\
\text { before } \\
\text { surgery }\end{array}$ & $\begin{array}{l}\text { 1d before } \\
\text { surgery }\end{array}$ & & $\begin{array}{c}\text { Intra- } \\
\text { operation }\end{array}$ & $\begin{array}{l}\text { 24h after } \\
\text { surgery }\end{array}$ & $\begin{array}{l}48 \mathrm{~h} \text { after } \\
\text { surgery }\end{array}$ & $\begin{array}{l}\text { 72h after } \\
\text { surgery }\end{array}$ & \\
\hline \multirow{3}{*}{$\begin{array}{l}\text { ENROLMENT: } \\
\text { Eligibility screen } \\
\text { Informed consent }\end{array}$} & & & & & & & & \\
\hline & & $\mathrm{x}$ & & & & & & \\
\hline & & $\mathrm{X}$ & & & & & & \\
\hline ALLOCATION: & & & $\mathrm{X}$ & & & & & \\
\hline \multicolumn{9}{|l|}{ INTERVENTIONS: } \\
\hline PCC & & & & $\mathrm{X}$ & & & & \\
\hline FFP & & & & $\mathrm{x}$ & & & & \\
\hline \multicolumn{9}{|l|}{ ASSESSMENTS: } \\
\hline \\
\hline $\mathrm{Hb}$ & $\mathrm{x}$ & & & $\mathrm{x}$ & $\mathrm{x}$ & $\mathrm{x}$ & $\mathrm{x}$ & \\
\hline Hct & $x$ & & & $x$ & $x$ & $\mathrm{x}$ & $x$ & \\
\hline PIt & $\mathrm{x}$ & & & $\mathrm{x}$ & $\mathrm{x}$ & $\mathrm{x}$ & $x$ & \\
\hline INR & $\mathrm{x}$ & & & $\mathrm{X}$ & $\mathrm{X}$ & $\mathrm{x}$ & $\mathrm{X}$ & \\
\hline PT & $\mathrm{x}$ & & & $\mathrm{x}$ & $\mathrm{x}$ & $\mathrm{x}$ & $\mathrm{x}$ & \\
\hline APTT & $x$ & & & $\mathrm{x}$ & $x$ & $\mathrm{x}$ & $\mathrm{x}$ & \\
\hline Fibrinogen & $\mathrm{x}$ & & & $\mathrm{X}$ & $\mathrm{x}$ & $\mathrm{x}$ & $\mathrm{x}$ & \\
\hline Blood biochemistry & $\mathrm{x}$ & & & $\mathrm{x}$ & $\mathrm{X}$ & $\mathrm{X}$ & $\mathrm{X}$ & \\
\hline \multicolumn{9}{|l|}{ Outcome variables: } \\
\hline Blood loss & & & & $\mathrm{X}$ & $\mathrm{X}$ & & & \\
\hline RBC transfusion & & & & $\mathrm{x}$ & $\mathrm{x}$ & $\mathrm{x}$ & $\mathrm{X}$ & $\mathrm{x}$ \\
\hline Re-exploration & & & & & $x$ & $\mathrm{x}$ & $\mathrm{x}$ & $\mathrm{x}$ \\
\hline
\end{tabular}

Figure 2 Study period. APTT, activated partial thromboplastin time; FFP, fresh frozen plasma; INR, international normalised ratio; PCC, prothrombin complex concentrate; PT, prothrombin time; RBC, red blood cell.

3. Developing coagulation factor deficiency or coagulopathic bleeding during the surgery, meeting the indications of PCC or FFP treatment.

4. Signing of the informed consent form.

\section{Exclusion criteria}

The exclusion criteria are as follows:

1. History of cardiac surgery.

2. Hepatic dysfunction before surgery.

3. Coagulopathy before surgery, including inherited or acquired coagulation factor deficiencies, thrombocytopenia, platelet dysfunction and other bleeding disorders.

4. Use of warfarin within 3 days and direct oral anticoagulants within 48 hours (or 72 hours if patient has renal impairment) before surgery.

5. Withdrawal of clopidogrel or aspirin less than 7 days and low molecular weight heparin less than 24 hours before surgery.

6. Allergy to allogeneic blood products.

7. Pregnancy.

8. Other serious diseases that may affect patient survival time, such as cancers.

\section{Randomisation and blinding}

Stratified randomisation will be used to assign the patients to two groups. The informed consents of those patients meeting the admission criteria will be obtained before surgery. Then patients will be randomly assigned to two groups by a specific computer randomisation system, when at least one of the following criteria is met: (1) INR >1.7 measured 20 min after CPB, (2) prolonged prothrombin time (PT) or activated partial thromboplastin time (APTT) ( $>1.5$ times baseline) measured 20 min after CPB and (3) excessive bleeding observed. Nurse anaesthetists will prepare the corresponding products for each patient according to the group assignments in an anaesthesia preparation room. PCC or FFP will be pumped into $50 \mathrm{~mL}$ syringes first, covered with opaque paper to hide the contents. For group PCC, we first diluted PCC to $50 \mathrm{~mL}$ with normal saline, and then supplemented subsequent volume using normal saline to make it equal to the corresponding required volume of FFP. The enrolment number of each patient will be marked on the syringes. Finally, the corresponding interventional products will be given to patients from syringes, 
followed by the light-protected infusion set. Participants, anaesthesiologists, surgeons and outcome assessors will all be blinded to the group assignments throughout the trial. In the case of the need for emergency rescue, if it is necessary to know the intervention for a participant, blinding will be broken. The allocation will be disclosed to healthcare providers in case of emergency in compliance with ethics considerations.

\section{Interventions}

Participants will be randomly assigned to two groups named the prothrombin complex concentrate group (group PCC) and the fresh frozen plasma group (control group or group FFP) respectively, with 297 cases in each group.

Preoperative management, anaesthetic and surgical techniques will be standardised for all patients. Various demographic as well as preoperative physiological and laboratory parameters will be recorded for each patient. During the operation, all patients will be under general anaesthesia. The surgical procedures will be performed through a median sternotomy approach, and CPB will be undertaken in a standardised fashion. A mild hypothermia condition $\left(32^{\circ} \mathrm{C}-34^{\circ} \mathrm{C}\right)$ will be achieved, and heparin $(400 \mathrm{IU} / \mathrm{kg})$ will be intravenously administered before initiation of $\mathrm{CPB}$, with activated clotting time (ACT) maintained above $480 \mathrm{~s}$ during CPB. In addition, tranexamic acid will be intravenously administered after the induction of anaesthesia until the end of the operation $(20 \mathrm{mg} / \mathrm{kg}$ for the first hour and $2 \mathrm{mg} / \mathrm{kg}$ thereafter). After CPB, circulating heparin will be antagonised with protamine sulfate at a ratio of $1 \mathrm{mg}$ of protamine per $100 \mathrm{IU}$ of heparin, making ACT within 130 s. Prolonged ACT will be treated with an additional dose of protamine sulfate. The cell saver machine will be used during surgery, and the following parameters should be checked and corrected off bypass as necessary: (1) patient's core temperature, (2) arterial blood gases, (3) post CPB coagulation screening results: (1) the platelet count, (2) the INR, (3) the APTT and PT and (4) serum fibrinogen levels. Off bypass, all patients' core temperatures will be raised above $37^{\circ} \mathrm{C}$.

PCC or FFP will be transfused when coagulation factor deficiency or coagulopathic bleeding is observed. In this study, the indications of PCC or FFP treatment include INR $>1.7$ or prolonged PT or APTT ( $>1.5$ times baseline) measured $20 \mathrm{~min}$ off-pump (ACT within $130 \mathrm{~s}$ ), or excessive bleeding observed during the surgery. ${ }^{22-24}$ In the presence of these conditions, 4-factor PCC (15 IU/ $\mathrm{kg})$ or FFP $(10 \mathrm{~mL} / \mathrm{kg})$ will be given according to the group assignments, guided by manufacturer's instructions and previous research. ${ }^{22}$ Half an hour after transfusion, the re-evaluation will be done and an additional dose will be administered if required. Other allogeneic blood products will be needed if cell saver is insufficient for patients, and transfusion will be guided by the haemoglobin concentration, the platelet count, the INR, the PT, the APTT and serum fibrinogen levels. Homologous
RBCs will be intraoperatively administered to maintain a haemoglobin concentration $>7 \mathrm{~g} / \mathrm{dL}$ or a haematocrit higher than $20 \%$. Platelets will be transfused when their count is $\leq 60 \times 10^{9} / \mathrm{L}$. Serum fibrinogen levels $<1.5 \mathrm{~g} / \mathrm{L}$ will be corrected with fibrinogen concentrate at doses of $25-50 \mathrm{mg} / \mathrm{kg}$. Additional blood product transfusions also will be performed at the discretion of the clinical team in the operating room.

After surgery, patients will be sent to the intensive care unit (ICU) and then back to the ward after their conditions stable. Patients' haemoglobin concentrations, haematocrit levels, platelet counts, INRs, PTs, APTTs, fibrinogen levels and blood biochemistry parameters will be monitored daily in the ICU. RBCs will be transfused if the haemoglobin concentration is $\leq 7 \mathrm{~g} / \mathrm{dL}$. Other blood product transfusions will be performed at the discretion of critical care physicians and surgeons based on patient conditions and laboratory test results.

Researchers who deliver the PCC or FFP to participants during the surgery will receive specific training to guarantee that the interventions are provided according to the randomised groups. The anaesthesia records, medical records and medical orders will be reviewed to confirm the interventions.

\section{Follow-up and withdrawal}

The study follow-up is scheduled as $24,48,72$ hours and 7 days after surgery, or discharge or death, whichever is first, to record observations relevant to the study and the results of laboratory testing. The laboratory tests will include the haemoglobin concentration, haematocrit level, platelet count, INR, PT, APTT, fibrinogen level and blood biochemistry parameters such as creatinine, aspartate aminotransferase and alanine aminotransferase concentrations. Blood loss will be recorded during the surgical procedure and within 24 hours after surgery. Other examinations will include electrocardiography, X-ray and echocardiography. Adverse events and serious adverse events (SAE) will be followed and collected within 30 days after surgery or death, whichever is first. EpiData software will be used for data entry and storage. Double data entry will be used to ensure data quality.

Every reasonable effort will be made to maintain protocol compliance and retain patient participation in the study. Participation will be terminated if the patient withdraws from the study. A study withdrawal form will be completed for these patients, and the reason for withdrawal will be captured. All subjects withdrawn from the study will be managed in accordance with the hospital's standard procedures.

\section{Outcomes}

Primary outcome

The primary outcome is the volume of blood loss during and within 24 hours after surgery. 


\section{Secondary outcomes}

The secondary outcomes include (1) the total units of allogeneic RBCs transfused during and within 7 days after surgery, (2) re-exploration due to postoperative bleeding within 7 days after surgery, (3) adverse events and SAEs within 30 days after surgery, and (4) length of ICU stay and hospital stay.

Intraoperative blood loss will be assessed by measuring the amount collected by aspiration and weighing the surgical gauze compresses. Blood loss from the floor, surgical gowns and surgical drapes are not included. Postoperative blood loss will be recorded as the blood volume collected through the suction drains at 24 hours.

\section{Statistical analysis}

Sample size

This is a clinical non-inferiority trial based on the hypothesis that PCC is not inferior to FFP in reducing perioperative blood loss in patients undergoing cardiac surgery under CPB. According to previous studies in our research team, the mean volume of blood loss during and within 24 hours after cardiac surgery under CPB is $726.3 \mathrm{~mL}$, and the standard deviation is $824.38 \mathrm{~mL}$. A non-inferiority margin is set at $200 \mathrm{~mL}$ based on clinical practice. To achieve $80 \%$ power at the $2.5 \%$ significance level, a sample size of 267 patients for each group is needed. Considering a $10 \%$ dropout rate, a total of 594 patients (297 per group) is necessary.

\section{Statistical methods}

Modified intent-to-treat analysis will be used for all valid variables. All randomised subjects in the study, regardless of adherence to the study process or whether an adverse event occurs before or after the intervention, should be included in the analysis. Sensitivity analysis will be performed to assess the bias that may be introduced due to non-adherence to the protocol or missing data. Baseline characteristics will be tabulated and compared between the PCC and FFP groups using standardised differences, and a value larger than 0.2 will be regarded as a clinically relevant difference between groups.

The primary outcome, the volume of blood loss during and within 24 hours after surgery, will be compared using the t-test with $\log$ transformation of the variable. Treatment effect will be measured by OR and mean difference for binary and continuous outcomes with corresponding 95\% CIs. No correction for multiple comparisons will be conducted in the analysis of the secondary outcomes; hence, the findings for secondary outcomes will be interpreted only as explanatory results. For safety outcomes, we will only describe the incidence of overall adverse events, SAEs and component adverse events without statistical tests between two groups. A two-sided $p$ value $<0.05$ was considered indicative of statistical significance.

\section{Adverse events}

Adverse events are defined as any undesirable event occurring in a patient during the study regardless of whether
Table 1 Classification of adverse events

\begin{tabular}{ll}
\hline Classification & Definition \\
\hline Mild & $\begin{array}{l}\text { With manifestations but no limitation of } \\
\text { physical activity }\end{array}$ \\
Moderate & With limitation of physical activity \\
Severe & Unable to carry on any physical activity \\
\hline
\end{tabular}

the event is considered to be related to PCC or FFP, such as thromboembolic events (including arterial and venous), perioperative myocardial infarction, renal dysfunction, hepatic dysfunction and neurological complications. All adverse events reported spontaneously by the patient or observed by the investigator or staff will be recorded and should be judged for relevance to the study intervention by researchers. A detailed description should be made and recorded in the summary report, including the date, manifestations, laboratory results, classification (table 1) and prognosis (table 2).

SAE is defined as any untoward medical occurrence or effect that results in death, is life-threatening (at the time of the event), requires hospitalisation or prolongs length of hospital stay, or results in persistent or significant disability or incapacity, or any other important medical event that does not result in any of the outcomes listed above due to medical or surgical intervention but could be based on appropriate judgement by the investigator. Any SAE should be recorded on the case report form. SAEs that occur from the beginning of the study to 24 hours after surgery should be reported to the Ethics Committee within 24 hours, even if it may not be associated with the study regimen. The related follow-up data should be reported to the sponsor after 24 hours.

\section{Protocol amendments}

The current protocol is V.3.0, date 21 September 2021. Any changes in the protocol during the trial that may affect the conduct of the trial, the safety and the benefit to patients will require a formal amendment to the protocol.

\section{Patient and public involvement}

This research will be done without patient involvement. Patients will not be invited to comment on the study design or contribute to the acquisition, analysis or interpretation of data for the work. Patients will not be consulted to develop relevant outcomes. Patients will not be invited to draft the manuscript for integrity or accuracy.

\begin{tabular}{|c|c|}
\hline Prognosis & Definition \\
\hline D & Death \\
\hline$P$ & Permanent or organic labour loss \\
\hline $\mathrm{H}$ & Hospitalisation \\
\hline $\mathrm{N}$ & None of the above \\
\hline
\end{tabular}




\section{DISCUSSION}

Coagulopathy is an important risk factor for bleeding and blood transfusion in patients undergoing cardiac surgery, associated with both early and late morbidity. Administration of FFP and PCC is current treatment regimens for clotting factor deficiency, which might be one of the major reasons of coagulopathy after CPB during cardiac surgery. ${ }^{14}$ Considering the advantages of PCC over FFP ${ }^{25-27}$ and the insufficiency of FFP in clinical practice setting, more and more research has been conducted to explore the efficacy and safety of PCC versus FFP in various conditions. ${ }^{28}{ }^{29}$ Till now, the use of PCC is recommended highly for severe bleeding from warfarin, as well as for patients undergoing urgent surgery or invasive procedures based on guidelines from several organizsations. ${ }^{23} 2430$

However, for perioperative bleeding and prolonged clotting times during cardiac surgery, the data are very limited. Several retrospective studies showed less perioperative bleeding and blood transfusion in patients with PCC, compared with FFP. In an observational study conducted by Cappabianca et $a l,{ }^{18}$ when 3-factor PCC was administered prior to chest closure or in the first few postoperative hours as a first-line treatment for post-CPB bleeding, there were less chest tube output and red cell transfusion versus FFP. In a retrospective cohort study, Arnékian et $a l^{31}$ showed that low-dose PCC (10 IU/kg) was associated with reduced blood loss during the initial hours after cardiac surgery. Patients who received combined FFP and PCC underwent more re-explorations than other groups. Clinical validation studies, such as properly designed RCTs still are needed to provide stronger evidence. So this time, we designed this RCT to explore the efficacy of PCC, compare with FFP, for the treatment of perioperative blood loss during general cardiac surgery.

In our study, we will choose the patients undergoing elective CABG, valve replacement or valvuloplasty through $\mathrm{CPB}$ in $\mathrm{Fu}$ Wai Hospital and Peking Union Medical College Hospital. Both hospitals are top medical institutions in China, with a large number of patients and standardised clinical diagnosis and treatment strategies, ensuring the feasibility and reliability of this study.

After obtaining the informed consents, patients meeting the administration criteria will be pre-enrolled and then actually enrolled and randomised into different groups (group PCC or group FFP) when meeting the indications of PCC or FFP treatment. According to guidelines and previous research, such indications include INR $>1.7$, prolonged PT or APTT ( $>1.5$ times baseline), or excessive bleeding observed during the surgery. ${ }^{22-24}$ In other words, any symptoms reflecting the coagulation factor deficiency or coagulopathic bleeding during the surgery will trigger the transfusion of PCC or FFP.

The recommended dose of PCC in guidelines is mainly used to reverse the effects of VKA and correct INR, ${ }^{162431}$ which is not quite suitable for our study. Patients included in our study will undergo non-complex cardiac surgery and will not be on anticoagulation therapy prior to surgery, so they rarely develop INR $>2$ and require such high level of PCC. ${ }^{32}$ To choose the proper dose of PCC, we first selected $10 \mathrm{~mL} / \mathrm{kg}$ for FFP according to the guidelines, ${ }^{23}{ }^{24}$ previous research ${ }^{22}$ and clinical practice. Then taking the dose balance of two intervention products, previous research which included similar patients as our study, ${ }^{22}$ and the manufacturer's instructions of PCC used in this study into consideration, we finally chose 15 IU/ $\mathrm{kg}$ for PCC.

The primary safety concern with PCCs has been their association with thrombogenic events such as stroke, myocardial infarction, pulmonary embolism, disseminated intravascular coagulation and deep vein thrombosis. ${ }^{33}$ A meta-analysis of 27 clinical studies involving 1032 patients presenting with bleeding or undergoing surgery showed that emergency reversal of warfarin with PCC was associated with a $1.4 \%$ incidence of thromboembolic events. The incidence was $1.8 \%$ with 4 -factor PCC (20 studies) and $0.7 \%$ with 3-factor PCC (seven studies), with a mortality rate of $10.6 \%{ }^{34}$ Although these events were associated with PCC administration, they could be attributed to the patients' underlying thrombotic risk factors in most cases. In addition, the already low incidence of such adverse events has further decreased over the last few years due to improvements in the composition of the more recent commercially available PCC (ie, inclusion of coagulation inhibitors, reduced use of activated coagulation factors, and improved balance of coagulation factors). Current evidence suggests that thromboembolic events and mortality are not increased with the use of PCCs. ${ }^{14}$

Our study also has several limitations. This is an exploratory study without pilot study before. The doses and time of intervention are based on guidelines and clinical practice, not having previous evidence in our own research team to provide stronger support. Further clinical validation studies for doses and time of PCC administration are needed to establish the most effective and safe way of administering PCC to patients undergoing cardiac surgery.

In conclusion, this study aims to identify the efficacy of PCC compared with FFP, exploring whether PCC is not inferior to FFP in reducing perioperative blood loss in patients undergoing cardiac surgery under CPB. Considering the gap of current research, our study will provide stronger clinical evidence and data support for PCC treatment in perioperative coagulopathy bleeding during general cardiac surgery, and also provide reference and guidance for clinicians in perioperative blood management during CPB.

\section{Author affiliations}

${ }^{1}$ Department of Anaesthesiology, Peking Union Medical College Hospital, Chinese Academy of Medical Sciences \& Peking Union Medical College, Beijing, China

${ }^{2}$ Outcomes Research Consortium, Cleveland, Cleveland, Ohio, USA 
${ }^{3}$ Department of Anaesthesiology, State Key Laboratory of Cardiovascular Disease, Fuwai Hospital, National Centre for Cardiovascular Diseases, Chinese Academy of Medical Sciences \& Peking Union Medical College, Beijing, China

${ }^{4}$ Medical Research Center, Peking Union Medical College Hospital, Chinese Academy of Medical Sciences \& Peking Union Medical College, Beijing, China

Contributors LP, CS and JS participated in the design and coordination of the study. CS, LP, HL, YZ and JS collected references and developed the protocol. CS, JS and YZ performed the statistical analysis. LP, CS and JS drafted the manuscript. All authors read and approved the final manuscript. LP and CS contributed equally to the manuscript.

Funding This research will be supported by Peking Union Medical College Hospital Precipitation and Integration Foundation (ZC201906511).

Disclaimer The funders had neither role in the design of the study, collection, analysis, interpretation of data, nor in writing the manuscript.

Competing interests None declared.

Patient and public involvement Patients and/or the public were not involved in the design, or conduct, or reporting or dissemination plans of this research.

Patient consent for publication Not applicable.

Ethics approval This study has been approved by the Institutional Review Board of Peking Union Medical College Hospital (ZS-2242). Written informed consent will be obtained from all subjects involved.

Provenance and peer review Not commissioned; externally peer reviewed.

Open access This is an open access article distributed in accordance with the Creative Commons Attribution Non Commercial (CC BY-NC 4.0) license, which permits others to distribute, remix, adapt, build upon this work non-commercially, and license their derivative works on different terms, provided the original work is properly cited, appropriate credit is given, any changes made indicated, and the use is non-commercial. See: http://creativecommons.org/licenses/by-nc/4.0/.

\section{ORCID iDs}

Chen Sun http://orcid.org/0000-0002-3903-0798

Yuelun Zhang http://orcid.org/0000-0001-7990-9003

\section{REFERENCES}

1 Parr KG, Patel MA, Dekker R, et al. Multivariate predictors of blood product use in cardiac surgery. $J$ Cardiothorac Vasc Anesth 2003;17:176-81.

2 Görlinger K, Shore-Lesserson L, Dirkmann D, et al. Management of hemorrhage in cardiothoracic surgery. J Cardiothorac Vasc Anesth 2013;27:S20-34.

3 Christensen MC, Krapf S, Kempel A, et al. Costs of excessive postoperative hemorrhage in cardiac surgery. J Thorac Cardiovasc Surg 2009;138:687-93.

4 Ferraris VA, Hochstetler M, Martin JT, et al. Blood transfusion and adverse surgical outcomes: the good and the bad. Surgery 2015;158:608-17.

5 Likosky DS, Zhang M, Paone G, et al. Impact of institutional culture on rates of transfusions during cardiovascular procedures: the Michigan experience. Am Heart J 2016;174:1-6.

6 Murphy GJ, Pike K, Rogers CA, et al. Liberal or restrictive transfusion after cardiac surgery. N Engl J Med 2015;372:997-1008.

7 Robich MP, Koch CG, Johnston DR, et al. Trends in blood utilization in United States cardiac surgical patients. Transfusion 2015;55:805-14.

8 Dyke C, Aronson S, Dietrich W, et al. Universal definition of perioperative bleeding in adult cardiac surgery. $J$ Thorac Cardiovasc Surg 2014;147:1458-63.

9 Ranucci M, Baryshnikova E, Castelvecchio S, et al. Major bleeding, transfusions, and anemia: the deadly triad of cardiac surgery. Ann Thorac Surg 2013;96:478-85.

10 Society of Thoracic Surgeons Blood Conservation Guideline Task Force, Ferraris VA, Ferraris SP, et al. Perioperative blood transfusion and blood conservation in cardiac surgery: the Society of thoracic surgeons and the Society of cardiovascular Anesthesiologists clinica practice guideline. Ann Thorac Surg 2007;83:S27-86.

11 Höfer J, Fries D, Solomon C, et al. A snapshot of coagulopathy after cardiopulmonary bypass. Clin Appl Thromb Hemost 2016;22:505-11.
12 Kaspereit F, Hoffmann S, Pragst I, et al. Prothrombin complex concentrate mitigates diffuse bleeding after cardiopulmonary bypass in a porcine model. Br J Anaesth 2010;105:576-82.

13 Raleigh L, Cole SP. Con: factor concentrate usage in cardiac surgery-a paucity of data limits their universal adoption. $J$ Cardiothorac Vasc Anesth 2018;32:1068-71.

14 Bhatt HV, Subramaniam K. Pro: prothrombin complex concentrate should be used in preference to fresh frozen plasma for hemostasis in cardiac surgical patients. J Cardiothorac Vasc Anesth 2018;32:1062-7.

15 Sarode R, Milling TJ, Refaai MA, et al. Efficacy and safety of a 4-factor prothrombin complex concentrate in patients on vitamin $\mathrm{K}$ antagonists presenting with major bleeding: a randomized, plasmacontrolled, phase IIIB study. Circulation 2013;128:1234-43.

16 Goldstein JN, Refaai MA, Milling TJ, et al. Four-factor prothrombin complex concentrate versus plasma for rapid vitamin $\mathrm{K}$ antagonist reversal in patients needing urgent surgical or invasive interventions: a phase 3B, open-label, non-inferiority, randomised trial. Lancet 2015;385:2077-87.

17 Demeyere R, Gillardin S, Arnout J, et al. Comparison of fresh frozen plasma and prothrombin complex concentrate for the reversal of oral anticoagulants in patients undergoing cardiopulmonary bypass surgery: a randomized study. Vox Sang 2010;99:251-60.

18 Cappabianca G, Mariscalco G, Biancari F, et al. Safety and efficacy of prothrombin complex concentrate as first-line treatment in bleeding after cardiac surgery. Crit Care 2016;20:20-5.

19 Song HK, Tibayan FA, Kahl EA, et al. Safety and efficacy of prothrombin complex concentrates for the treatment of coagulopathy after cardiac surgery. J Thorac Cardiovasc Surg 2014;147:1036-40.

20 Weinberger J, Cipolle M. Optimal reversal of novel anticoagulants in trauma. Crit Care Clin 2017;33:135-52.

21 Arnékian V, Camous J, Fattal S, et al. Use of prothrombin complex concentrate for excessive bleeding after cardiac surgery. Interact Cardiovasc Thorac Surg 2012;15:382-9.

22 Ortmann E, Besser MW, Sharples LD, et al. An exploratory cohort study comparing prothrombin complex concentrate and fresh frozen plasma for the treatment of coagulopathy after complex cardiac surgery. Anesth Analg 2015;121:26-33.

23 Kozek-Langenecker SA, Afshari A, Albaladejo P, et al. Management of severe perioperative bleeding: guidelines from the European Society of Anaesthesiology. Eur J Anaesthesiol 2013;30:270-382.

24 Tibi P, McClure RS, Huang J, et al. STS/SCA/AmSECT/SABM update to the clinical practice guidelines on patient blood management. $J$ Cardiothorac Vasc Anesth 2021;35:2569-91.

25 Franchini M, Lippi G. Prothrombin complex concentrates: an update. Blood Transfus 2010;8:149-54.

26 Vigué B, Ract C, Tremey B, et al. Ultra-rapid management of ora anticoagulant therapy-related surgical intracranial hemorrhage. Intensive Care Med 2007;33:721-5.

27 Levy JH, Tanaka KA, Dietrich W. Perioperative hemostatic management of patients treated with vitamin $\mathrm{K}$ antagonists. Anesthesiology 2008;109:918-26.

28 Wong JK, Chen PC, Falvey J, et al. Anticoagulation reversal strategies for left ventricular assist device patients presenting with acute intracranial hemorrhage. Asaio J 2016;62:552-7.

29 Cosgrove $\mathrm{RH}$, Patanwala AE, Sears BL, et al. The use of three factor prothrombin complex concentrate to reverse warfarin treated mechanical circulatory device patients immediately prior to heart transplant. J Heart Lung Transplant 2015;34:S54-5.

30 Pagano D, Milojevic M, Meesters MI, et al. 2017 EACTS/EACTA guidelines on patient blood management for adult cardiac surgery. Eur J Cardiothorac Surg 2018;53:79-111.

31 Arnékian V, Camous J, Fattal S, et al. Use of prothrombin complex concentrate for excessive bleeding after cardiac surgery. Interact Cardiovasc Thorac Surg 2012;15:382-9.

32 Green L, Roberts N, Cooper J, et al. Prothrombin complex concentrate vs. fresh frozen plasma in adult patients undergoing heart surgery - a pilot randomised controlled trial (PROPHESY trial). Anaesthesia 2021;76:892-901.

33 Ansell J, Hirsh J, Hylek E. Pharmacology and management of the vitamin K antagonists: American College of chest physicians evidence-based clinical practice guidelines (8th edition). Chest 2008;133.

34 Dentali F, Marchesi C, Giorgi Pierfranceschi M, et al. Safety of prothrombin complex concentrates for rapid anticoagulation reversal of vitamin $\mathrm{K}$ antagonists. A meta-analysis. Thromb Haemost 2011;106:429-38. 